\title{
Normal y anormal: discursos y prácticas de la segregación
}

\author{
Normal and abnormal: \\ discourses and practices of segregation
}

\section{Resumen}

El propósito principal de este artículo reflexivo es analizar las consecuencias que se derivan de los discursos y prácticas que tienen relación con los llamados conceptos de normalidad y anormalidad en los debates actuales en las Ciencias Sociales.

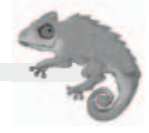

Palabras clave: discursos, prácticas, normalidad, anormalidad.

\begin{abstract}
The central purpose of this essay is to analyze the consequences of the discourses and practices related to the so-called concepts of normality and abnormality in current social science debates.
\end{abstract}

Keywords: Discourses, practices, normality, abnormality.

Recibido el 13 de junio de 2012 y aprobado el 25 de junio de 2012 .

1 Psicólogo de la Universidad Javeriana. Formación en Psicoanálisis en el Campo Freudiano. Actualmente cursando la Maestría de Estudios Sociales, en la Universidad del Rosario, Bogotá D.C. 
"Quería de verdad abrir la puerta, deseaba sinceramente dejarse ver $y$

hablar con el apoderado; estaba deseoso de saber lo que los otros, que tanto deseaban verle, dirían ante su presencia. Si se asustaban, Gregorio no tendría ya responsabilidad alguna y podría estar tranquilo, pero si lo aceptaban todo con tranquilidad entonces tampoco tenía motivo para excitarse..."

Franz Kafka, La Metamorfosis

$\mathrm{P}$ ara la comprensión de este texto es necesario plantear, de entrada, la discusión de lo normal y lo anormal como construcción que tiene un carácter histórico. Cuando el filósofo francés Michel Foucault enseña en la cátedra "Historia de los sistemas de pensamiento", inaugurada el 2 de diciembre de 1970, su curso llamado Los Anormales en los años 1974-1975, nos introduce en la genealogía del concepto mismo, señalando un origen que surge: "del cruce de tres elementos: el monstruo humano, el individuo a corregir y el onanista" (2006, p. 299). Tres casos que se presentan como problemáticos al poder, en el siglo XIX, que llevarán a elaborar discursos y prácticas de control que buscarán ser legitimadas.

De entrada y como se ha enunciado, hay dos aspectos a considerar cuando se habla de la oposición normal-anormal. Se trata de lo que procede de ellos, en el orden discursivo y, por otro lado, en el orden de las prácticas que surgen de dicho discurso. Para darle una secuencia lógica a esta exposición, se hará una división, a partir de estos dos órdenes, pasando por varios autores para explicarlos y extraer las consecuencias que se derivan, como pertinentes para el debate actual en las Ciencias Sociales.

\section{Lo discursivo como ideología de lo "desviado"}

El ejemplo dado por Foucault en Los Anormales (2006) se anuda a otro trabajo de este filósofo de Poitiers, en un texto fundamental para entender los orígenes del discurso de la anormalidad. Tal texto se llama La bistoria de la locura en la época clásica (1998). En éste, el autor lleva a develar el carácter histórico de la locura como forma "desviada" de lo cotidianamente aceptado como saludable. En el tercer volumen del libro Foucault muestra las distintas explicaciones que se le intentan dar a la locura, como, por ejemplo, aquella causada por los cambios de clima o por las fases lunares (1998, p. 19). 
Desde esta mirada va, poco a poco, virando a explicaciones que dan muestra de un cambio, como en el caso del pensamiento griego, de lo mítico a lo lógico, con dilucidaciones que explican la locura como: "la irrupción de la animalidad (naturaleza), en el ámbito de la cultura y del hombre" (Foucault, 1996, p. 26).

Paulatinamente, la posibilidad de inteligibilidad de la locura se sofisticará con el refinamiento del diagnóstico en el campo psiquiátrico, de manera que: "se pasó de la locura, como error, como aquella en la que el hombre pierde la verdad, a la locura en la que el hombre pierde la verdad de sí mismo" (Foucault, 1996, p. 38). En esta cita puede verse cómo se transita de una explicación exterior al sujeto, a una que le atribuya a él mismo la razón de su enajenación. El discurso va siendo construido, de manera que los términos usados dejen de pasar por lo cotidiano, por lo pedestre y, aparentemente, por lo moral, para convertirse en conceptos que se ubican en una esfera que, cada vez más, pretende ser neutralmente valorativa.

En esta misma línea de pensamiento, varios autores siguen su razonamiento. Dos de ellos son la argentina Carolina Ferrante y el español Miguel Ferreira. La primera es doctora en Ciencias Sociales de la Universidad de Buenos Aires y el otro es doctor en Sociología de la Universidad Complutense de Madrid. En su escrito Cuerpo y Habitus: el marco estructural de la experiencia de la discapacidad (2011), estos dos autores, inspirados en los aportes de Bourdieu, se preguntan si no será que las taxonomías, en el campo de la salud, ancladas en la díada normal-anormal, se traducen en otras como bello-feo o bueno-malo (Ferrante \& Ferreira, 2011, p. 90). Ello da pie a concederle a la discapacidad, como forma de cuerpo "anormal", un carácter axiológico que la coloca como no virtuosa, ya que, según ellos: "la 'normalidad' (bondad, belleza, salud, capacidad) es incorporada como naturaleza devenida virtud" (2011, p. 92). De otro lado, señalan que: "el habitus de la discapacidad es [...] un producto histórico, a partir del cual el Estado inculca la concepción de cuerpo legítimo, definida por el campo médico" (2011, p. 90).
Como puede verse, los discursos, tanto alrededor de la locura como de la discapacidad, tienen fuertes raíces en explicaciones que tienden a ser circulares, en la medida en que se acuñan conceptos que vienen de un saber legitimado, como el de la medicina, que le da el carácter de verdad y de validez a tales discursos en el campo social. En otras palabras, el peso y la legitimidad de ciertas clasificaciones no están desligados de un saber que tiene un peso, socialmente hablando. Dicho peso se debe a un proceso que Foucault denominó medicalización, entendido como un desarrollo histórico y político en la Europa de los siglos XVIII y XIX, en el que la medicina entra en el funcionamiento general del discurso y el saber científico, a través de una medicina colectiva, social y urbana (1977, p. 18). El concepto de medicalización ayuda a entender cómo la práctica médica entra en el orden social, pero su entrada tiene un alto costo y es la posibilidad de la intromisión de la misma en los asuntos más privados del cuerpo, con la excusa de pretender analizar los efectos del medio en el organismo y, en últimas, el organismo mismo.

Lo anterior es también ilustrado por el filósofo y médico francés Georges Canguilhem, maestro de Foucault y alumno de Gastón Bachelard. En su texto Lo normaly lo patológico muestra cómo la enfermedad, en tanto que correlato de lo patológico, de lo desviado (para su época): "ya no es objeto de angustia para el hombre sano, sino que se ha convertido en objeto de estudio para el teórico de la salud" (Canguilhem, 2005, p. 20). Ello significa que la enfermedad no es más una preocupación por el bienestar, sino que se ha convertido en un objeto de estudio y de las persona que se encuentran enfermas.

La fascinación por lo extraño de la enfermedad es explicada por Canguilhem como la atracción de la ciencia por lo irregular, ocupándose de regularidades, es decir, que la definición misma de lo patológico, como correlato de lo anormal, está dada desde lo regular, lo considerado parte de la norma. Lo normal, de alguna manera, desde una explicación en la lógica, es la regla que está confirmada por la excepción. De lo anterior se 
podría concluir parcialmente que la dupla normal-anormal está sostenida en una oposición, a la manera de los personajes del dramaturgo francés Jean Genet en su obra El Balcón. Cada personaje es definido por su opuesto en el gran prostíbulo: el Juez, por ejemplo, requiere de criminales para llevar a cabo su labor.

El desplazamiento de la enfermedad, como problema particular de quien la sufre, hacia un problema poblacional requirió, además de discursos, de instituciones que legitimaran dichos discursos. Instituciones que se convirtieran en fortines que construyeran un saber que justificara sus enunciados, a partir de un interés marcadamente político y económico, tal como lo recuerda Foucault en la Historia de la Locura: "La locura deja de ser extraña y se llena de significaciones psicológicas que le dan sentido a un deseo burgués de hacer del internamiento una práctica legitimada" (1996, p. 71). La unión de la locura, como discurso psicológico, con el discurso jurídico va generando una lógica en la que se decide quién tiene derecho a circular por el mundo libremente y quién debe ser recluido.

De igual forma, las instituciones psiquiátricas, tal como las presenta el sociólogo canadiense Erving Goffman, en su texto Internados, construyen una "semántica muy variada y tiene recursos para todas las situaciones [...] algunas traducciones verbales corrientes en los hospitales psiquiátricos no representan términos médicos aplicados a las prácticas disciplinarias, sino más bien un uso disciplinario de prácticas médicas" (1972, p. 374). Este autor señala que al interior de las instituciones psiquiátricas se da un proceso de desculturización de los sujetos internados, de manera que el discurso médico es un "todo" separado del "afuera" que se refuerza a sí mismo en un proceso de autovalidación.

Este mismo presupuesto es presentado por el sociólogo francés Loïc Wacquant, alumno de Bourdieu, quien en su texto Las Cárceles de la Miseria muestra un panorama actual de cómo: "la creación de los objetos de estudio prefabricados está dada para validar 'verdades' que den peso a lo ideológico" (2004, p. 63). El centro de grave- dad de su argumento está en el carácter político y económico de un Estado que se ha propuesto ejercer un control penal, dejando atrás su apuesta paternalista, pero que, según este autor, no ha renunciado a ejercer control, sólo que ahora lo hace por medios que sean justificables, como el discurso de la "seguridad". Señala el autor que: "las nuevas nociones de Estado redujeron su papel social y endurecieron su papel penal, bajo el pretexto de la seguridad, en términos físicos y no de riesgo de vida (salarial, social, médico, educativo, etc.)" (Wacquant, 2004, p. 22). Para el logro de este objetivo fue necesario todo un discurso que justificase diferencias que fuesen avaladas por un aparataje institucional, tipificando comportamientos deseables y comparándolos con los no deseables. Para ello, se ha valido de la psicología social, por ejemplo, cuando se intenta mostrar a la delincuencia como relacionada a factores de carencias mentales o morales y no porque haya carencias materiales que incidan en ella (Wacquant, 2004, p. 27).

De otro lado, la afirmación frente a la cual el acervo de metáforas que se van creando alrededor de cualquier hecho desconocido, pone en evidencia que hay una pretensión de clasificación, jerarquización y, en últimas, que merced a un rasgo particular se pueda ser señalado y etiquetado. Esto es lo que presenta Goffman, quien como representante del denominado Interaccionismo Simbólico, en la obra Estigma: la identidad deteriorada, aporta la consideración frente a la cual un estigma es "un atributo profundamente desacreditador". A su vez, añade que: "un atributo que estigmatiza a uno, puede confirmar la normalidad del otro" (1963, p. 13). Dichas afirmaciones llevan a pensar que en las relaciones que se dan, de entrada, merced al estigma, genera separaciones, fracturas en el modo de relación social, principio de la segregación. El señalamiento al otro como anormal no lleva sólo a su separación del conglomerado, su aislamiento, sino que "confirma" a aquel que señala como el individuo "normal".

Por último, es preciso traer a la discusión los aportes del sociólogo estadounidense Howard Becker, quien también forma parte de los pen- 
sadores del Interaccionismo Simbólico. A partir de su obra Outsiders indica cómo el concepto de desviado es algo que los científicos sociales no se han preguntado, en tanto que etiqueta, ¿se trata, acaso, de ser desviado respecto a las reglas de grupo? Esto es algo que se pregunta (1966, p. 3), e intenta responder señalando que la desviación es creada por los grupos sociales, construyendo las reglas cuyas infracciones constituyen la desviación y aplicándolas a gente particular, llamándolos "anormales" (1966, p. 9). No obstante, señala que las reglas de la desviación no son universalmente acordadas, de manera que lo que para unos puede ser considerado "anormal", para otros no.

De esta manera, puede concluirse que, a la manera de la pieza teatral del dramaturgo polaco Slawomir Mrocek, llamada La Policía, el uso del poder, en el ámbito social, debe estar reglamentado y avalado por un discurso que esté muy bien elaborado, de manera que sea "naturalizado" y que sea "digerible" y casi impensable por la sociedad. La estigmatización de un grupo que se convierte en enemigo justifica su encierro y proscripción de lo compartido por la mayoría. Para ello, son necesarios discursos que estén sustentados en instituciones que los vehiculicen. Los discursos sin instituciones que funjan como oficializadoras de sus contenidos sólo son sentido común. Se requiere analizar la dicotomía normal-anormal con la de centro-periferia para entender que los saberes están ubicados de forma estratégica en el mapa social, de manera que se excluya todo saber y discurso que intente poner en cuestión un oficialismo que pretende ejercer un control por la vía de lo simbólico.

\section{Las prácticas y su forma de hacer "carne" lo discursivo}

El texto de Mrocek, como lo recuerda Esslin en su libro The Theater of the Absurd, relata cómo un Estado X está tras la persecución de sus enemigos y cuando, finalmente, los ha eliminado a todos, hace que la policía se disfrace de enemigo para seguir justificando su acción y el gasto de su presupuesto (Esslin, 1983, p. 318). El señalamiento, como forma de estigma, devela el carácter de práctica misma de la estigmatización.

Si tenemos en cuenta lo que Foucault dice en su texto Genealogía del Racismo respecto del saber, podemos ver que los discursos, en el mundo burgués, no se interesan por el loco o el niño, lo que interesa de ellos es el ejercicio mismo del poder (1992, p. 42), es decir, que la contracara de lo discursivo es el ejercicio mismo del poder, como práctica que hace efectivo dicho discurso.

No obstante, es importante precisar que el discurso y su práctica concomitante están insertos en una lógica de relación social más macro. En este caso, se trata de estar en el mundo, basado en la relación del capitalismo. Desde esta perspectiva, puede entenderse por qué el sociólogo francés Loïc Wacquant, discípulo de Pierre Bourdieu, en su texto La Miseria del Mundo, trae ejemplos de los Estados Unidos, como paradigma de este sistema económico. Él señala que el proyecto de "seguridad" nace allá y que se requirió de todo un aparataje mediático y propagandístico para hacer de este discurso una realidad que fuese aplicada por todo el mundo; igualmente, se generaron lógicas de espacios públicos para estigmatizar a los homeless, los graffiteros, las prostitutas y a los expendedores de drogas.

En este orden de ideas, un planteamiento hecho por Carolina Ferrante y Miguel Ferreira en su texto Cuerpo y Habitus afirma que: "la sociedad capitalista se basa en el secuestro corporal y la expropiación experiencial" (2011, p. 91), de manera que el cuerpo que creemos nuestro es apropiado por la lógica de mercado. No parece ser posible pensar el cuerpo sin la captura discursiva ejercida sobre él ni la posibilidad de ejercicio autónomo, pues, como se ha señalado, el cuerpo es proclive a ser señalado si se sale de los estándares que lo social impone como lo apropiado.

Entonces, el concepto de estigma deviene una práctica y Goffman mismo dice que apare- 
cen prácticas que garantizan la "corrección" de comportamientos o rasgos anómalos. De esta forma, la psicoterapia o la cirugía estética están hechas para corregir lo que a los ojos propios y de los otros es un defecto. Señala que la propaganda del estigma es tan fuerte que hay una interiorización del propio estigma como desviación, de manera que la persona misma que ha sido señalada de anormal termine creyéndolo.

No obstante, el estigma, en el mundo capitalista, puede capitalizarse como un beneficio secundario, de forma tal que aquel que es señalado como diferente puede sacar provecho de éste, obteniendo un beneficio secundario (Goffman, 1963, p. 22). El estigma, entonces, también se convierte en mercancía que puede circular en el mundo para beneficio de alguno.

De igual forma, puede pensarse que el creciente uso del estigma ha dado pie a que aparezcan nuevas profesiones (Goffman, 1963, p. 40) y nuevos campos de estudio, cosa que está en consonancia con lo que señalaba Foucault respecto a lo que llamaba medicalización. La necesidad de curar u orientar a aquellos que están fuera de la norma ha generado prácticas que históricamente son nuevas. Son cada vez más comunes nuevas terapias, nuevos grupos que se identifican entre ellos y que se asocian a partir de su desgracia por ser señalados como distintos.

Valiéndose las instituciones, como ya se dijo, de discursos que deben ser renovados, por cuanto el lenguaje podría evidenciar sesgos ideológicos, pretenden colocarse en un lugar de neutralidad, pasando de llamar "gamines" a los que hoy llama "ciudadanos de calle", en el caso colombiano, por ejemplo. Los discursos mutan, pero las prácticas institucionales se reafirman para justificar su existencia. Es por ello que Goffman, en su texto Internados (1972), se pregunta si las instituciones psiquiátricas siguen valiendo para lo que fueron creadas y se responde que ellas, más que tener un método de ajuste, tienen uno de desajuste. Los médicos se auto validan para hacer aceptable su labor, de cara a la sociedad (1972, p. 61).
La capilaridad del proceso de dominación, a partir de discursos estigmatizados, llega a través de las instituciones a lo más micro del ámbito social. La socialización del género en la literatura, la televisión o los juguetes, o la socialización de la naturaleza, como en el caso del embarazo manipulado, la ingeniería genética, son ejemplos que trae el sociólogo británico Anthony Giddens, en su texto Sociología (2000). Él se interesa por una mirada holística de las sociedades y en este texto se ocupa del debate de género y sexualidad, afirmando que: "el proceso de aprendizaje de la 'desviación' suele verse acentuado por las mismas organizaciones que, supuestamente, se encargan de corregir las conductas desviadas, como las cárceles y los reformatorios" (2000, p. 238).

De otro lado, Giddens abre la discusión alrededor de la dupla naturaleza-cultura, cuando discute los conceptos de sexo, género y biología. Señalar, por ejemplo, aspectos de la sexualidad, tomados desde la Biología, para calificarlos de anormales es un error por cuanto el género corresponde a una construcción social y, por ende, se encuentra condicionado por los aspectos relacionales y contextuales. No es posible aparejar el sexo con el género porque este último no tiene correlato en lo biológico (1982, p. 138).

De igual forma, Foucault, en La Historia de la Locura, hace un análisis similar alrededor de la locura. Él nos recuerda que: "la locura ha sido posible por todo lo que el medio ha reprimido en el hombre de su existencia animal" (1998, p.27). Dicha sentencia, como la citada de Giddens, evoca el carácter evolucionista y biologicista que sirven como argumento valedero para legitimar prácticas de segregación en contextos que abogan por la desaparición de lo polisémico, de lo divergente.

\section{Conclusiones}

Después de este recorrido por algunos autores contemporáneos, es importante resaltar algunos aspectos concluyentes que pueden servir 
para determinar el alcance del debate normalanormal en el contexto de las Ciencias Sociales, en la actualidad.

En primer lugar, es conveniente señalar que hay una proliferación de discursos, desde finales del siglo XVIII, que han apuntado a acuñar las categorías de normal-anormal. Estos discursos son heredados, fundamentalmente, del campo de la medicina y la psiquiatría.

En segundo lugar, estos discursos han encontrado su aval en la confluencia de otros, como el jurídico, para hacerlos mucho más robustos y capaces de ser más convincentes, de manera que no se encuentre contradicción a su interior y que varias disciplinas converjan en las mismas afirmaciones, naturalizándolo.

De otro lado, es necesario la presencia de instituciones que le den su aval, de manera que lo hagan circular, pero que, fundamentalmente, le den su "tarjeta de presentación" ante la sociedad. Sin la presencia de instituciones respetables, aparatos ideológicos como los llamaba Althusser, para producir y reproducir estos dis- cursos, para hacer los sutiles giros lingüísticos que se requieren para "humanizarlos", los discursos no tendrían el efecto que tienen.

De igual forma, los discursos se constituyen en el guión que sirve de base para la puesta en escena de las prácticas que le "dan vida". Las prácticas se apoyan en lo discursivo, encarnándose en lo cotidiano, en una red de interrelaciones que pasan por el cuerpo. Los mecanismos de control que buscan el disciplinamiento del cuerpo son esos discursos que existen en las prácticas.

Por último, es primordial recordar que todo esto se da en un contexto: el capitalismo. Éste determina formas de relación donde todo puede ser potencialmente capitalizable. Las prácticas al interior de este sistema económico se dan a partir de la mercantilización de todo, desde el cuerpo hasta aquello que es objeto de estigmatización. Las profesiones que viven de lo anormal proliferan, como proliferan las clasificaciones que multiplican las patologías que, a su vez, devienen en nuevos objetos de estudio de la ciencia y nuevos objetos de venta para el capitalismo. 


\section{Referencias bibliográficas}

Becker, H. (1996). Outsiders. New York: The Free Press.

Canguilhem, G. (2005). Lo normal y lo patológico. México D.F.: Siglo XXI.

Esslin, M. (1980). The Theatre of the Absurd. Middlesex: Penguin Books.

Ferrante, C., \& Ferreira, M. (2011). Cuerpo y habitus: el marco estructural de la experiencia de discapacidad, en Revista sociológica de pensamiento crítico, 5(2), 85-101. Recuperado de http://www.mferreira.es/Documentos_nuevo/Publicaciones.htm

Foucault, M. (1977). Historia de la medicalización, en Educación Médica y Salud Vol 11 (No 1). Recuperado de http://www.terceridad.net/Sistemasdesalud/Foucault, $\% 20$ M. $\% 20$ His toria $\% 20$ de $\% 201$ a $\% 20$ medicalizaci\%F3n.pdf
(1992). Genealogía del Racismo.

Madrid: La Piqueta. (1998). Historia de la locura en la época clásica. Bogotá: FCE. . (2006). Los Anormales. México D.F.: FCE.

Genet, J. (1983). El Balcón. Madrid: AlianzaLosada.

Giddens, A. (2000). Sociología. Madrid: Alianza.

Goffman, E. (1972). Internados. Buenos Aires: Amorrortu.

(1963). Estigma. La identidad deteriorada. Buenos Aires: Amorrortu.

Wacquant, L. (2004). Las Cárceles de la Miseria. Buenos Aires: Manatial. 